Military Technical College Kobry El-Kobbah, Cairo, Egypt

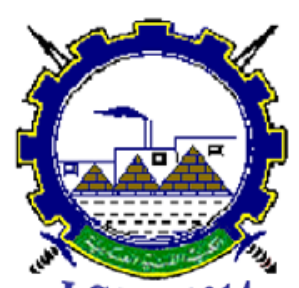

I.C.E.E.2014 $7^{\text {th }}$ International Conference

on

Chemical \& Environmental

Engineering

27 - 29 May, 2014.

\title{
CEEC-2
}

\section{Corrosion Behaviour Of AA2024 COATED WITH An Acid- Soluble Collagen/Hybrid Silica Sol-Gel Matrix}

\author{
Mohamed Gobara*, and Hesham Kamel
}

\begin{abstract}
Collagen is a potential corrosion inhibitor for aluminium alloy 2024 (AA2024), being derived from fish scale. FTIR analysis confirms the extraction of collagen. The extracted collagen powder was dissolved within hybrid silica sol-gel forming an environmentally friendly (green) coating. Corrosion behaviour of silica sol-gel (SOL) and collagen/silica sol-gel (CSOL) coated AA2024 in 3.5\% $\mathrm{NaCl}$ solution was investigated by electrochemical impedance spectroscopy (EIS). In addition, the mechanical properties of both coatings were evaluated using impact test, hardness, micro-hardness resistance, mandrel bend test and cross cut adhesion test. Results showed that collagen improves the corrosion resistance of the coated AA2024, while maintaining the mechanical properties of the silica sol-gel coating.
\end{abstract}

\section{Keywords:}

Corrosion, collagen, FTIR, AA2024, EIS

* Egyptian Armed Force, Kobry Elkobba, Cairo, Egypt 


\section{Introduction}

Aluminium, with its high electronegative standard electrode potentiaf $(-1600 \mathrm{mV})$, has a high affinity for Oxygen forming a stable uniform passive oxide film on its surface. This passive oxide film prevents corrosion of the underlying metal on the basis that if this film is scratched, the underlying metal is oxidized and a new oxide film is generated at the scratch site. However, aluminium alloys [1] are usually susceptible to localised corrosion (pitting corrosion) caused by the breakdown of the passive film. Aluminium 2024 alloy (AA2024) is one of the most widely used alloys in the aerospace industry due to its high strength to weight ratio and good fatigue resistance [2]. However, this alloy suffers from a lack of corrosion resistance due to the presence of copper $(3.8-4.9 \%)$ being the main alloy strengthening addition. Chromate (VI) conversion coatings have been widely used for many decades to protect aluminium alloys from corrosion. However, due to them being toxic and carcinogenic, they are becoming increasingly restricted within Europe and North America [3].

Consequently, the new trend in corrosion protection technology is to replace these coatings with environmentally friendly coatings such as sol-gel coatings [4-6]. These coatings not only form inorganic structures but they can also form hybrid organic/inorganic network structures. These hybrid coatings combine scratch, wear resistance, durability and impact strength associated with inorganic coatings [7-9], with that of flexibility, low temperature curability and adhesion associated with organic coatings [10,11].

Silica sol-gel coatings can form Van der Waals bonds with the metallic surface, which can be transformed to stable covalent Me-O-Si bond during the drying process. Applying silica sol-gel coatings can protect aluminium from corrosion due to the formation of silica rich Al-oxide film which blocks the pores of Al oxide film hence, forming a highly corrosionresistant layer [12]. Appropriate additives are required to provide the active corrosion inhibition offering self-healing properties of the coated surface [13, 14]. Most of these effective inhibitors can be adsorbed on the metal surface [15-17] forming strong co-ordination bond with the metal atom and/or forming a passive film on the surface [18]. However, only a few environmentally friendly compounds have been investigated as corrosion inhibitors [1922].

Collagen is the most abundant protein in vertebrates constituting about $30 \%$ of the total proteins. It has a wide range of applications in cosmetic, biomedical material and pharmaceutical applications [23-25].

In this current study collagen has been used as an additive to silica sol-gel coatings in order to form a protective film on AA2024 alloy subject to immersion in neutral $3.5 \% \mathrm{NaCl}$. The corrosion behaviour of the prepared sol-gel/collagen coating has been compared with that of identical silica sol-gel coating without the addition of collagen. In addition, the mechanical properties, namely macro and micro hardness, of both coatings have been investigated using ASTM standard test methods The ability of coated samples to resist cracking when subjected to bending loads has been evaluated using a simple mandrel bend test. Finally, a cross-hatch test has been used to evaluate the adhesion of the coating to the metallic surface.

\section{Experimental}

\subsection{Material}

Aluminium alloy 2024-T3 samples (obtained from Q-panel $2.54 \times 10.16 \times 0.156 \mathrm{~cm}$ ) were cleaned with deionised water followed by ultrasonic cleaning in acetone and then drying for $30 \mathrm{~min}$ at $70^{\circ} \mathrm{C}$ before applying the coating. 


\subsection{Preparation of collagen}

Collagen was extracted from fish scale according to that prepared by Prabjeet et al [27]. The scales of Nile tilapia fish were washed with distilled water at $5^{\circ} \mathrm{C}$ then mixed with $0.1 \mathrm{M}$ sodium hydroxide at a ratio of 1:10 scales to alkali solution to remove non-collagenous proteins. The mixture was continuously stirred for 6 hours in an ice bath. The treated scales were continuously washed with distilled water until a neutral $\mathrm{pH}$ of the washed water was reached. The scales were then soaked in $0.5 \mathrm{M}$ acetic acid for 24 hours and filtered and the filtrates were collected. Finally, The collagen was precipitated by adding $\mathrm{NaCl}$ to the filtrate in the presence of $0.05 \mathrm{M}$ tris-(hydroxymethyl) aminomethane, to neutralize the solution ( $\mathrm{pH}$ 7.0) and then the collagen powder was collected by centrifuging the solution.

\subsection{Preparation of collagen/silica sol-gel coating}

The silica sol-gel solution was prepared by an acid-catalyzed hydrolysis and condensation process of precursors; tetraethoxysilane (TEOS) and 3-Glycidyloxypropyl trimethoxysilane (GPTMS) purchased from Sigma Aldrich, USA. TEOS and GPTMS were mixed in ethanol with the molar ratio of 0.02: 0.09: 5.0 respectively. The mixture was stirred for $30 \mathrm{~min}$. before the acid $\left(\mathrm{HNO}_{3}\right)$ catalyst. The $\mathrm{pH}$ was adjusted by adding $0.1 \mathrm{M} \mathrm{HNO}_{3}$ to a value of 2 before increasing the temperature. The mixture was then vigorously stirred at $80{ }^{\circ} \mathrm{C}$ until it turned to a clear sol (SOL). For the collagen/silica (CSOL), a similar procedure was carried out; with the exception that $0.5 \mathrm{~g}$ of collagen is dissolved in the $0.1 \mathrm{M} \mathrm{HNO}_{3}$ before the acid is added to the precursor mixture. Both sols allowed to stand for approximately one week before film deposition on the $\mathrm{Al}$ alloys substrate. The coating was applied using a spray coating technique, following which the coating was dried at $80^{\circ} \mathrm{C}$ for 16 hours.

\subsection{Corrosion measurements}

Corrosion tests were carried out in a three-electrode cell using the sample as the working electrode and a saturated calomel electrode (SCE) and a platinum electrode as reference and counter electrodes respectively. Electrochemical impedance measurements were obtained at the measured $E_{\text {оср }}$ values applying $\pm 10 \mathrm{mV}$ perturbation in the frequency range from $1 \times 10^{5}$ to $10^{-2} \mathrm{~Hz}$. Electrochemical corrosion measurements were performed separately in naturally aerated 3.5\% $\mathrm{NaCl}$ at room temperature using a Gamry ${ }^{\circledR} 600$ instrument. The experimental results of the impedance were analysed in terms of an equivalent circuit using a nonlinear least squares fit technique provided by the Gamry ${ }^{\circledR}$ software.

\subsection{Mechanical testing}

The mechanical properties of coatings were evaluated in order to estimate the behaviour of the proposed coating under normal service operating conditions. Several mechanical tests have been conducted in accordance with ASTM standards. For each test three samples have been used and the average value calculated. Impact performance has been measured according to the ASTM D6905 standard. The mandrel bend test is used to rate the ability of coated samples to resist cracking when bent under loads which they may be subjected to during service life. The test samples in the form of sheets are bent under steel mandrels with varying diameters. Test samples in the form of $70 \times 150 \times 0.5 \mathrm{~mm}$ coated panels have been used according to the ASTM D522 / D522M - 13 standards. . The pendulum test measures the hardness resistance of coated rigid surfaces. The test uses a pendulum that is 
allowed to swing freely on two balls resting on the coated test sample. The hardness is then measured by the number of oscillation cycles the pendulum will swing until it reaches complete stop. The pendulum test has been performed according to the Konig pendulum hardness test in accordance with the ASTM D4366-95 standard. The Rockwell C macrohardness test has been performed according to the ASTM E18 -12 standard, while the Knoop indentation has been used to measure the micro-hardness according to the ASTM D1474-98 standard. The Knoop indenter used in the form of a rhombic-based pyramidal diamond supplied a $50 \mathrm{~g}$ test weight, and then the indent size is measured using a high powered microscope. The cross hatch technique is used to evaluate the adhesion of a coating to the metallic surface. Thin cuts are applied to the coating and a pressure-sensitive tape is applied to this area and then removed. The tape is then visually inspected for the presence of any delaminated coating.

\section{Results and discussion}

\subsection{Collagen characterization}

Fourier Transmission Infra Red (FTIR) spectrum of the prepared collagen powder from the skin of tilapia is depicted in the Fig. 1. The bands represented at a wavenumbers of 1460, 1408, 1060 and $590 \mathrm{~cm}^{-1}$ correspond to $\mathrm{CH}_{2}$ bond bend, COO- symmetrical stretch, C$\mathrm{O}$ stretch and skeletal stretch respectively. The amide I band is found at $1658 \mathrm{~cm}^{-1}$ and is associated with the stretching vibrations of the carbonyl group $(\mathrm{C}=\mathrm{O}$ bond $)$. The amide $\mathrm{A}$ was found at a wavenumber of $3430 \mathrm{~cm}^{-1}$ and represents a free $\mathrm{N}-\mathrm{H}$ stretch vibration of a peptide which involves a hydrogen bond. The amide B band is found at wavenumbers of 2928 and $2075 \mathrm{~cm}^{-1}$ representing the asymmetrical stretch of $\mathrm{CH}_{2}$. The FTIR results indicate that the prepared sample is acid soluble collagen [23, 27-30]

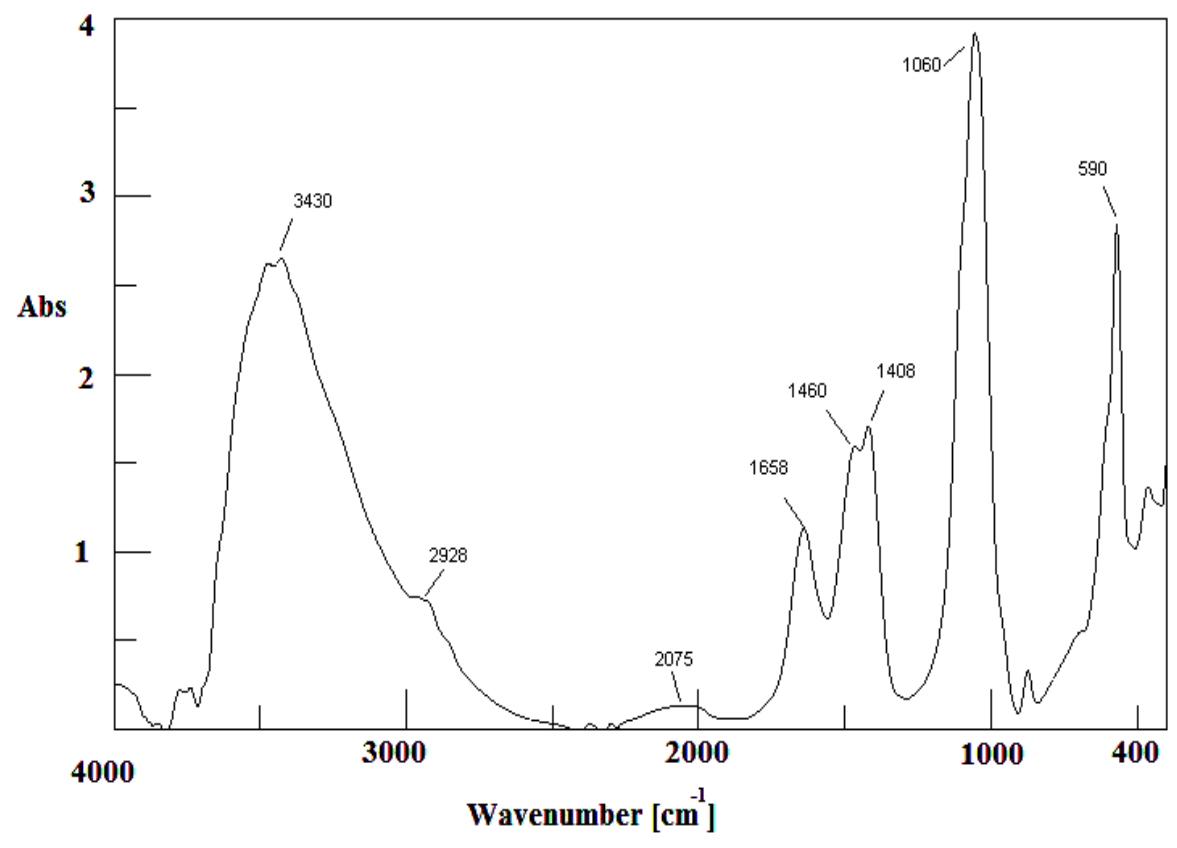

Fig. 1 FTIR spectrum of the prepared acid soluble collagen 


\subsection{Morphology of the coatings}

Before studying the corrosion performance of the sol-gel coated AA2024, scanning electron microscopy (SEM) was used to investigate sol-gel surface morphology. The SEM images of the SOL and CSOL coated AA2024 sample Fig. 2 (a and b), shows that the surfaces of the coatings were free from cracks and appeared to be uniform.
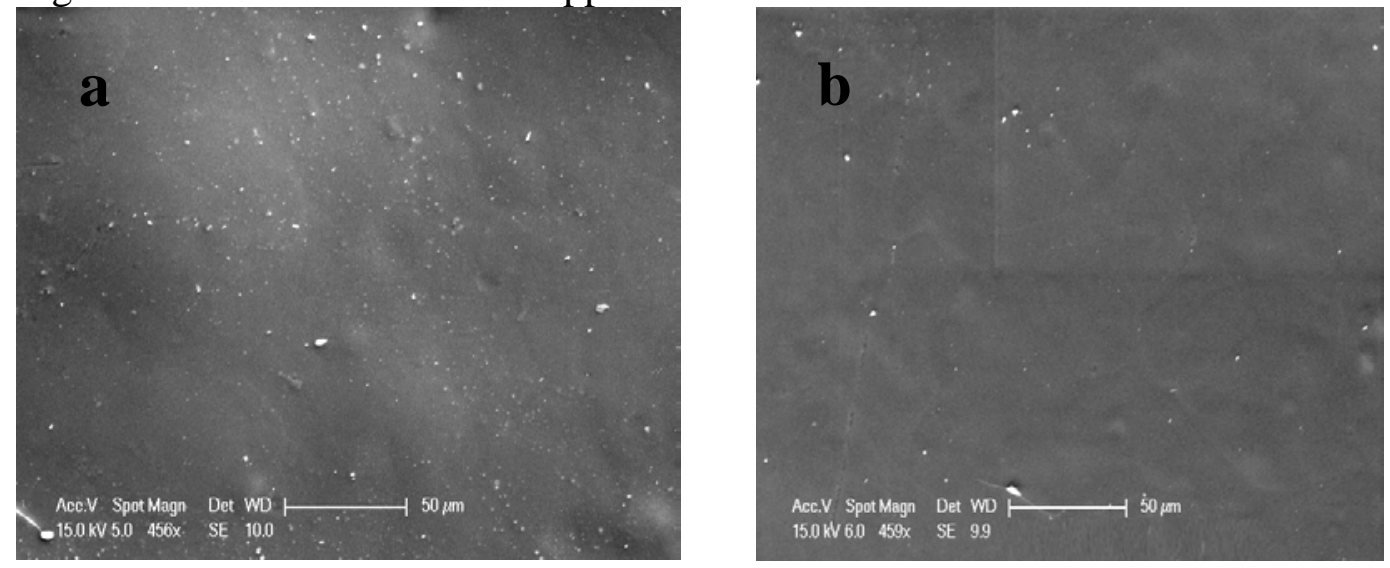

Fig. 2 SEM image of AA2024 coated with (a) SOL (b) CSOL

Fig. 3 presents SEM images, of the cross sections of the SOL and CSOL coated AA2024 samples show the coating to have a thickness around 14-16 $\mu \mathrm{m}$. Both SEM images indicate that there are no voids and the coatings (SOL and CSOL) seem to have good adhesion with the metal substrate (adhesion properties will be discussed later). A back-scatter electron image and EDX elemental maps of the cross section of the CSOL coated sample, indicate the location of both the alloy and coating, see Fig. 4
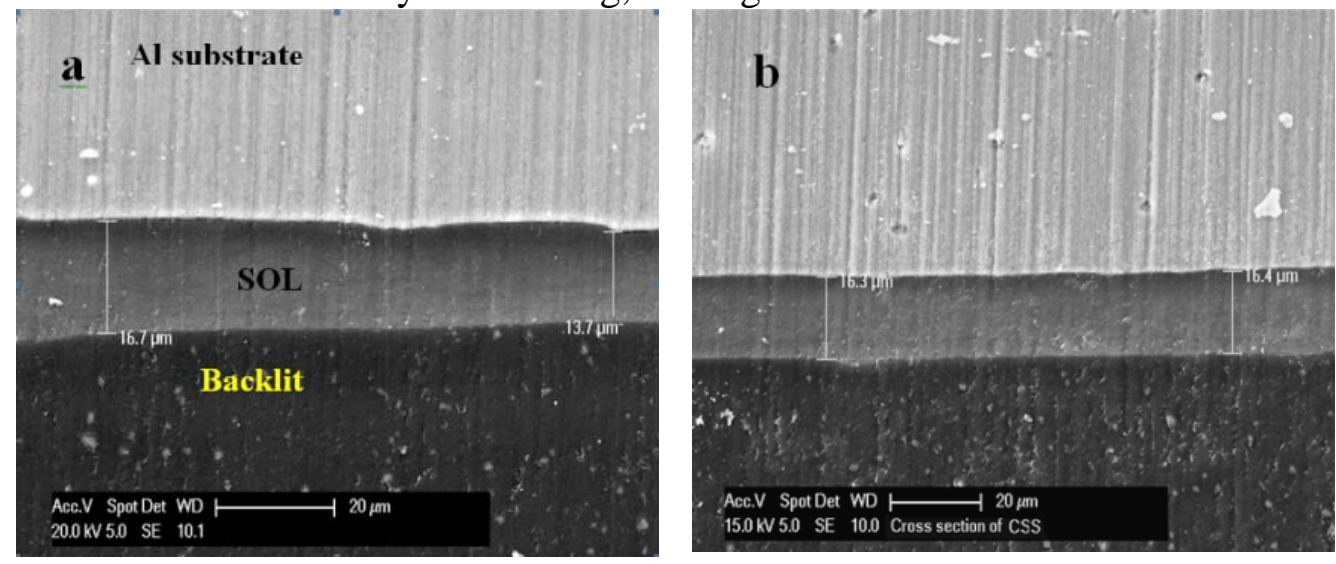

Fig. 3 SEM image of cross section of AA2024 coated with a) SOL b) CSOL

\begin{tabular}{|l|l|}
\hline SE/ESB, 255 & Cu La, 43 \\
\hline
\end{tabular}




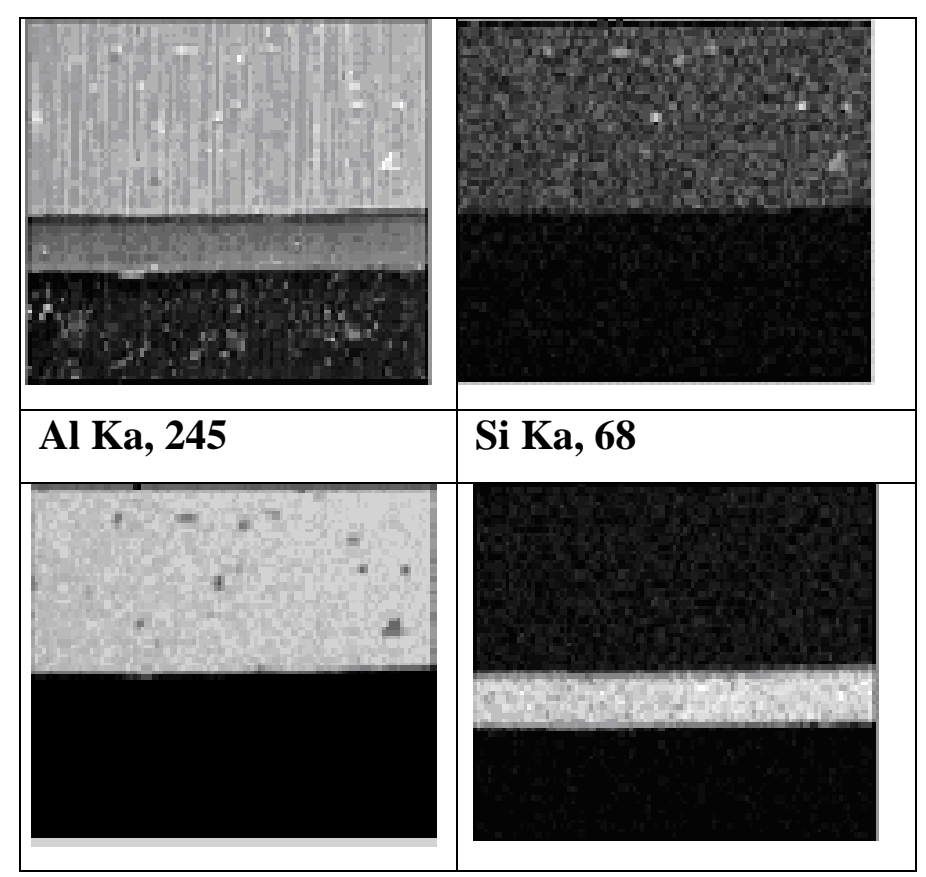

Fig. 4 EDX mapping of CSOL coated AA2024 sample

\subsection{Corrosion behaviour of the coated samples}

The corrosion properties of SOL coated sample were investigated using EIS in $3.5 \% \mathrm{NaCl}$. Fig. 5 shows that the impedance at the beginning of immersion is high (over $10^{5} \mathrm{Ohm} . \mathrm{cm}^{2}$ ). However, with prolonged immersion, the impedance value decreases by more than one order of magnitude within 14 days. 


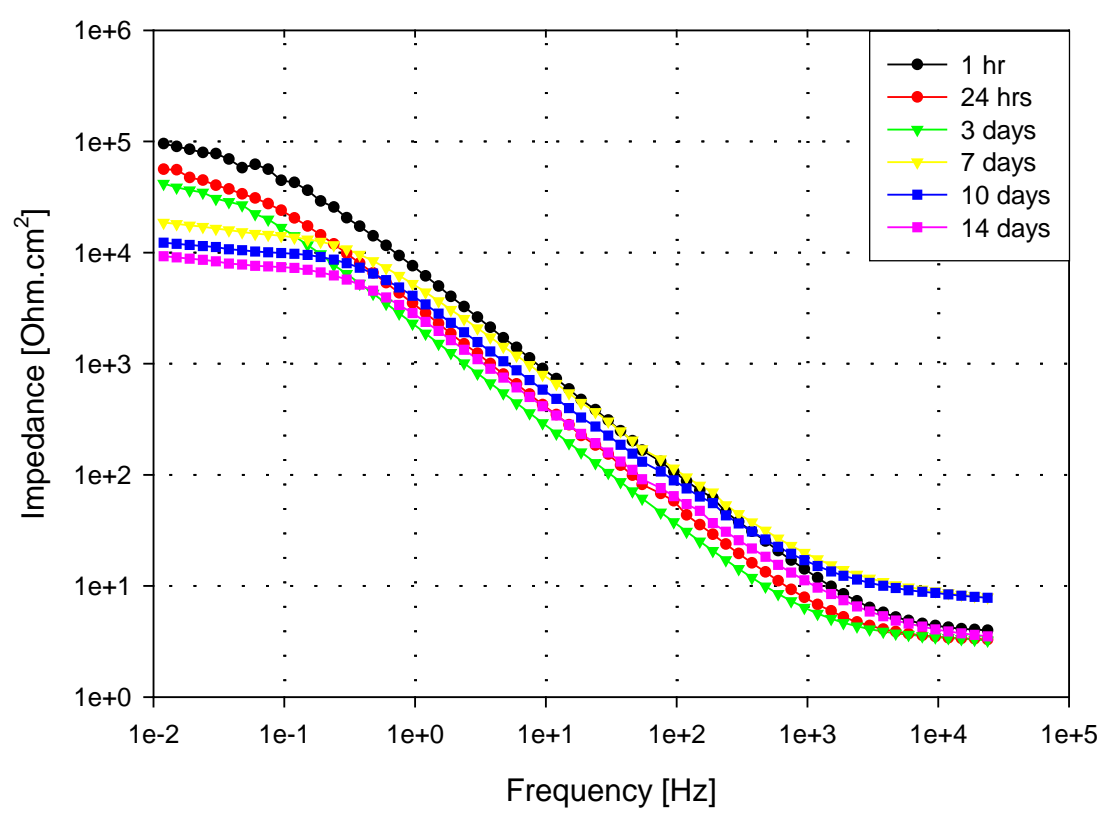

Fig. 5 Impedance of SOL coated AA2024 in 3.5\% NaCl

Fig. 6 shows the phase angle curve of SOL where it has two time constants; at $3 \times 10^{4} \mathrm{~Hz}$ and at $10 \mathrm{~Hz}$ after $24 \mathrm{hrs}$ of immersion. The former represents the outer layer of coating which decreased with immersion time. This time constant shows a decreasing capacitive behaviour which may be related to lose of the hydrophobic property of SOL [31-33]. The second time constant peak, at $10 \mathrm{~Hz}$, decreases by prolonged immersion inferring diffusion of electrolyte through the coating [34]. Finally a new time constant begin to appear after seven days of immersion at low frequency $(0.5 \mathrm{~Hz})$. With prolong immersion time, the magnitude of the new time constant increases combined with a decrease in both capacitive and resistive region impedance values, suggesting an increase in the area of the substrate exposed to the electrolyte as a sign of breakdown of the SOL coating.[35]. 


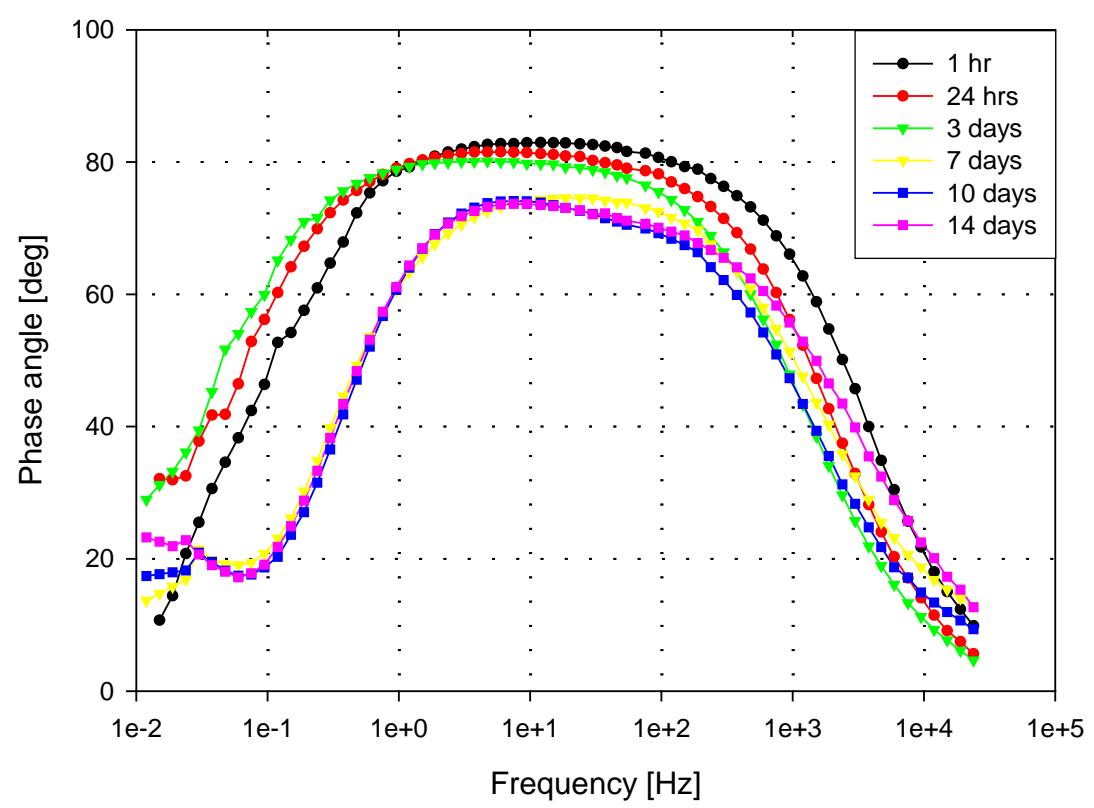

Fig. 6 Phase diagram of SOL coated AA2024 in 3.5\%NaCl

This behaviour was accompanied by the appearance of pits (Fig. 7-a) after 10 days of immersion in the electrolyte. In addition it can be noted that numerous bubbles are observed within the coating (see arrows in Fig. 7-b) that represent growing pits underneath the sol-gel coating. The colour of the pits changed from white, after 10 days, to dark brown after 14 days. The EDX mapping of the pitting corrosion, Fig. 8, shows that the sol-gel coating is completely rupture at the pit due to presence of the corrosion products.
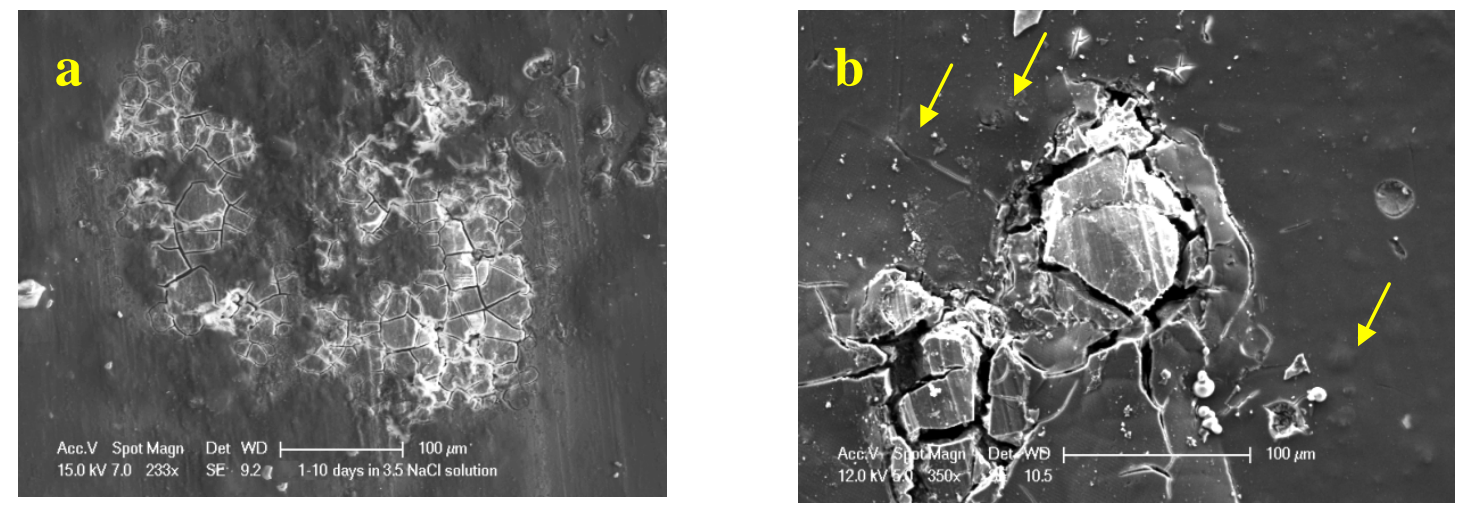

Fig. 7 SEM image of SOL coated AA2024 sample after immersion in 3.5\% NaCl solution for (a) 10 days and (b)14 days 

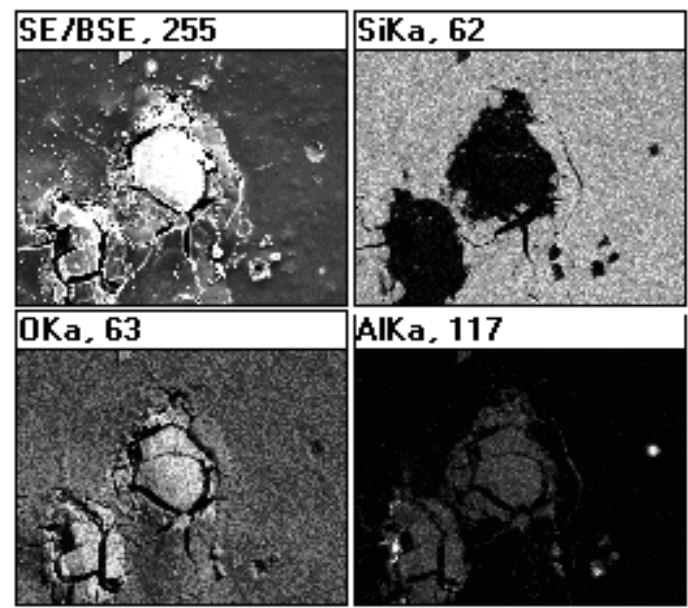

AlKa, 117

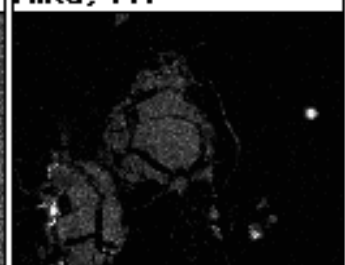

Fig. 8 EDX mapping of the pitting corrosion after 14 days immersion, as shown in Fig. 7

This behaviour may relate to the diffusion of the corrosive electrolyte to the metal/coating interface resulting in pitting. This pitting process may be related to the inhomogeneous distribution of $\mathrm{Cu}$ combined with the presence of other intermetallic particles $\left(\mathrm{Al}_{2} \mathrm{CuMg}\right.$, $\mathrm{AlCuMnFe}$ and $\left.\mathrm{AlCu}_{2}\right)$ creating local galvanic cells that can act as anodic or cathodic sites with respect to aluminium matrix [36].

The investigation of the corrosion performance of the CSOL sample is carried out using EIS in $3.5 \% \mathrm{NaCl}$ solution for up to five weeks. The coating impedance, Fig. 9, shows a small change at the high frequency range $\left(3 \times 10^{4} \mathrm{~Hz}\right)$ during immersion in the corrosive solution, notably the impedance decreased from 18 to 5 Ohm. $\mathrm{cm}^{2}$. However, the impedance at mid and low frequency range $\left(10^{-2}\right.$ to $1 \times 10^{2}$ $\mathrm{Hz}$ ) maintains a stable manner that decreases less than a half order of magnitude during five weeks of immersion.

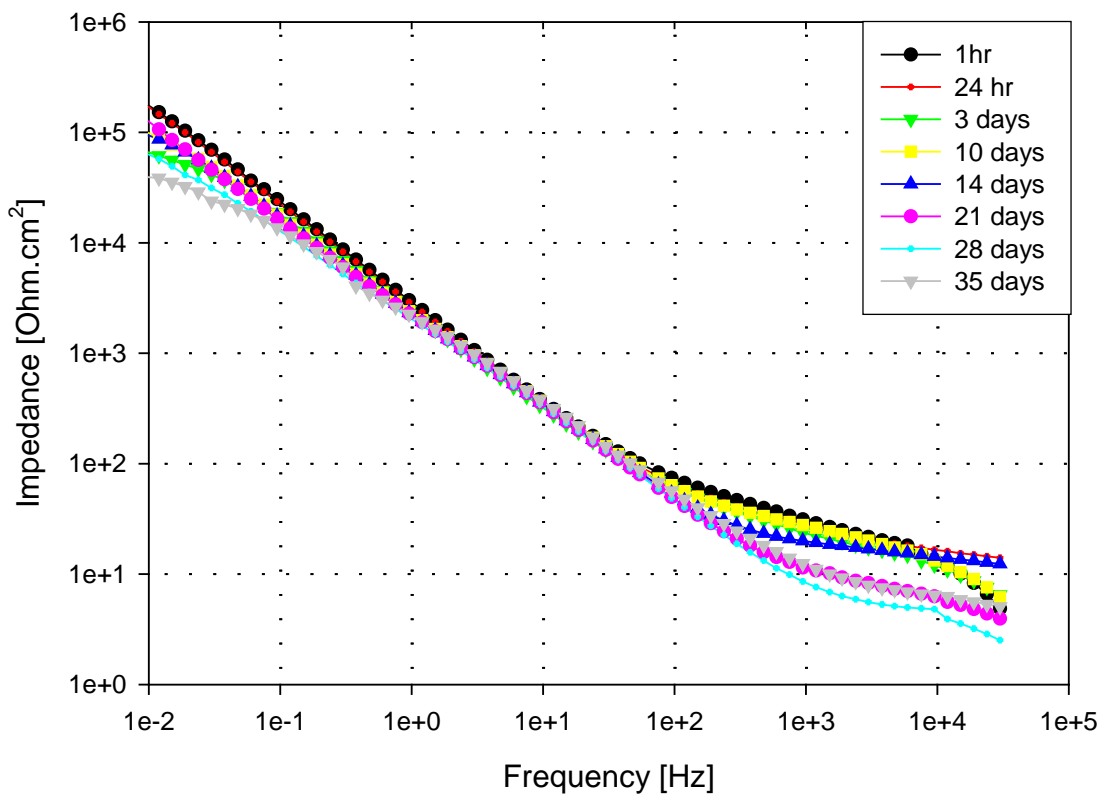

Fig. 9 Impedance of CSOL coated AA2024 in 3.5\% NaCl 
The phase angle curve of the CSOL samples represents in Fig. 10. It shows two time constants at $10^{3}$ and $1.0 \mathrm{~Hz}$ during the first day of immersion. The former related to the coating/solution interface which decreases during immersion. The position of latter time constant peak remains stable during the immersion period. Although the capacitive behaviour of this time constant displays a decrease during five weeks of immersion, it does not affect the corrosion performance of coating, where visual inspection of the CSOL coated AA2024 indicates absence of pitting or delamination after five weeks of immersion in $3.5 \% \mathrm{NaCl}$ solution.

The phase angle curve shown in Fig. 10, highlights the stability of impedance at both the mid and low frequencies range of $1 \times 10^{2}$ to $1 \times 10^{-2} \mathrm{~Hz}$ for up to 28 days.

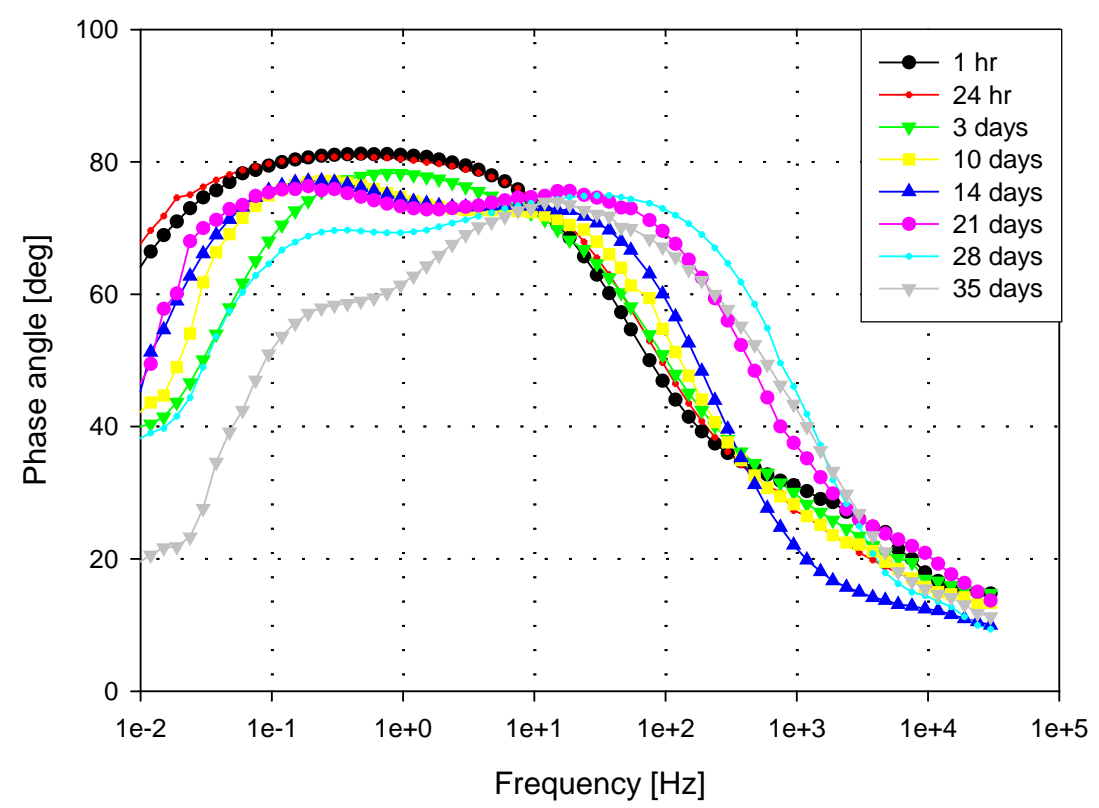

Fig. 10 phase diagram of CSOL coated AA2024 in 3.5\% NaCl

Fig. 11 shows an SEM image of AA2024 coated with CSOL after 35 days of immersion in $3.5 \% \mathrm{NaCl}$ solution. The image clarifies the stability of the coating during immersion where there is no sign of pitting or delamination. 


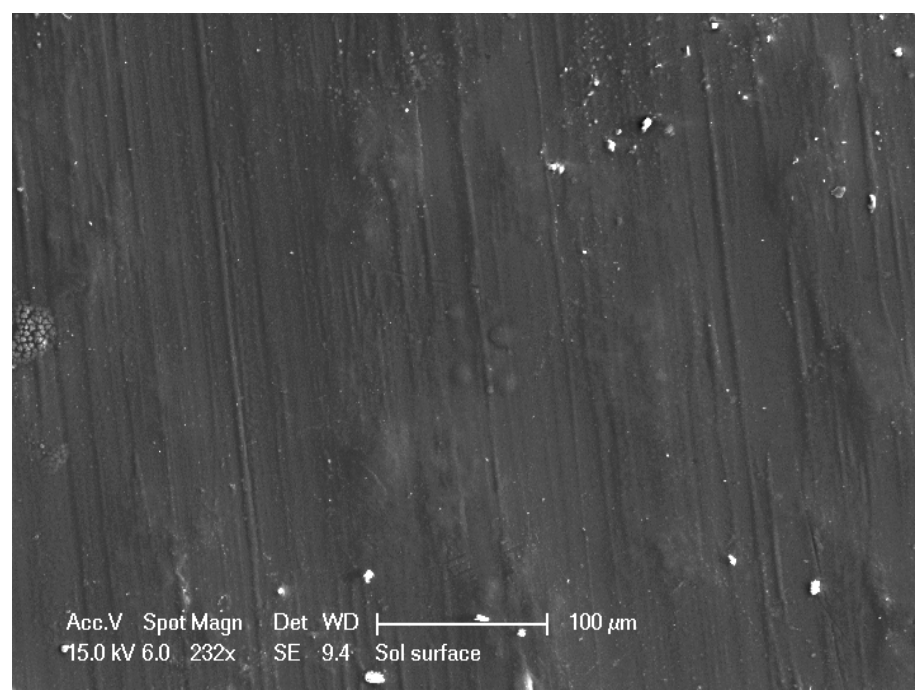

Fig. 11 SEM image of CSOL coated AA2024 sample after immersion for 35 days in $3.5 \% \mathrm{NaClsolution.}$

Fitting the EIS data to an equivalent electrical circuit allows an understanding of the corrosion process occurring within the coating system. The EIS equivalent circuit shown in Fig. 12 is typical of that of an organic barrier coating, and is considered as applicable to this coating. This circuit contains the following components; an electrolyte resistance $\left(R_{\mathrm{S}}\right)$; pore SOL layer resistance $\left(R_{\mathrm{p}}\right)$; SOL coating capacitance $\left(Q_{\mathrm{c}}\right)$, double layer capacitance $\left(Q_{\mathrm{dl}}\right)$ and charge transfer resistance $\left(R_{\mathrm{ct}}\right)$. Moreover, constant phase elements (CPEs) were used instead of pure capacitors.

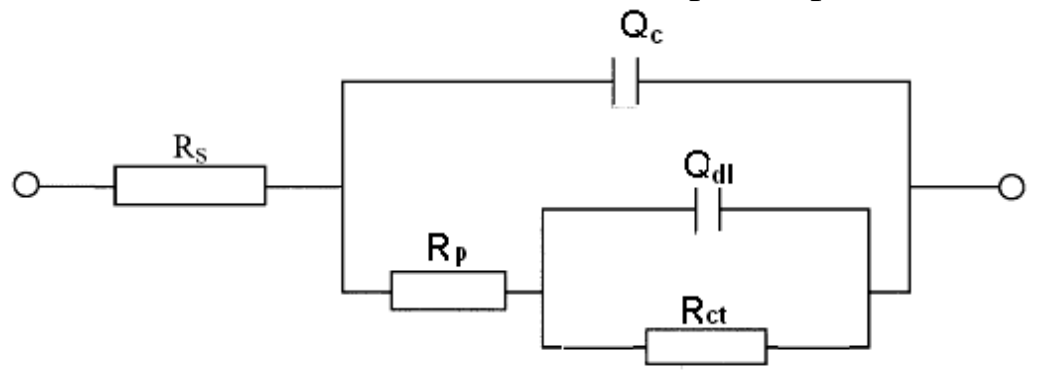

Fig. 12 Equivalent circuits used for numerical fitting of the EIS data for a

CSOL?

coated AA2024 in $3.5 \% \mathrm{NaCl}$ solution

To compare the capacitive behavior of the different coating systems, first obtained values of the constant phase elements (CPEs) parameters , $Y_{0}$ and $n$, then convert them to an ideal capacitance values, $C_{\mathrm{dl}}$, according to the following equation [37].

$$
C_{d l}=\frac{Y_{0} \omega^{n-1}}{\sin (n \pi / 2)}
$$

where $Y_{0}$ is the $C P E$ constant, $\omega$ is the angular frequency $(\mathrm{rad} / \mathrm{s}), \mathrm{j}^{2}=-1$, which is an imaginary number and $n$ is the $C P E$ exponent. For ideal electrodes, the $C P E$ is equal to an ideal capacitor when $n=1$

The charge transfer resistance, $R_{\mathrm{ct}}$, of the SOL coated AA2024 system increases at the beginning of immersion test which may due to formation of an oxide 
layer, however, $R_{\mathrm{ct}}$ decreases continuously during the rest of immersion time as shown in Fig. 13. At the same time, the double layer capacitance $\left(C_{\mathrm{dl}}\right)$ increases gradually with immersion time as also shown in Fig. 13. The decrease of charge transfer resistance and increase of double layer capacitance may be attributed to electrolyte ingress within the coating. These experimental results indicate a rapid break down of the sol-gel coating in 3.5\% $\mathrm{NaCl}$ solution within a few days of immersion. The sol-gel did not demonstrate any long-term protection under immersion in artificial seawater and pits appeared on the entire surface after 7 days followed by rupture of the coating. These results indicate that the sol-gel coating is a poor barrier coating for AA2024 having limited corrosion protection properties for the AA2024.

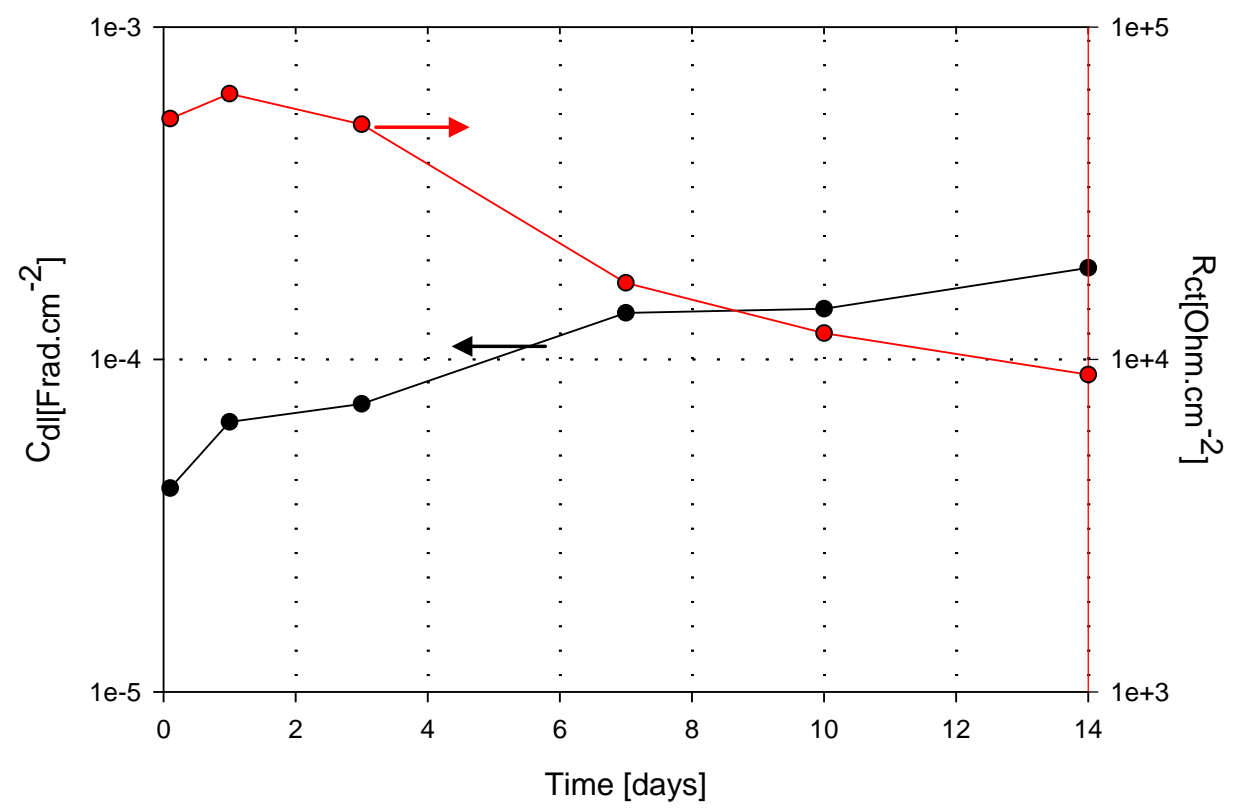

Fig. 13 Change of double layer capacitance and charge transfer resistance of SOL coated AA2024 in 3.5\% NaCl solution with immersion time

To understand the corrosion behaviour of these CSOL coatings, the EIS data of CSOL coated AA2024 were fitted into a circuit as shown in Fig. 12.

Fig. 14 shows the change of pore resistance and coating capacitance with time of immersion for CSOL coated AA2024. The coating shows a sharp decreasing in $R_{\mathrm{p}}$ during first day of immersion while the value of the coating capacitance shows an increase. After this start, $R_{\mathrm{p}}$ slightly decreases up to the rest of immersion test, in the same time $C_{\mathrm{c}}$ slightly increases. This behaviour explains the slight decrease of impedance at high frequency, $10^{4} \mathrm{~Hz}$, (see Fig. 9) during immersion. This change in $R_{\mathrm{p}}$ and $C_{\mathrm{c}}$ may be related to the loss of hydrophobic properties and increasing water uptake of the collagen/sol-gel coating during immersion in the corrosive solution. 


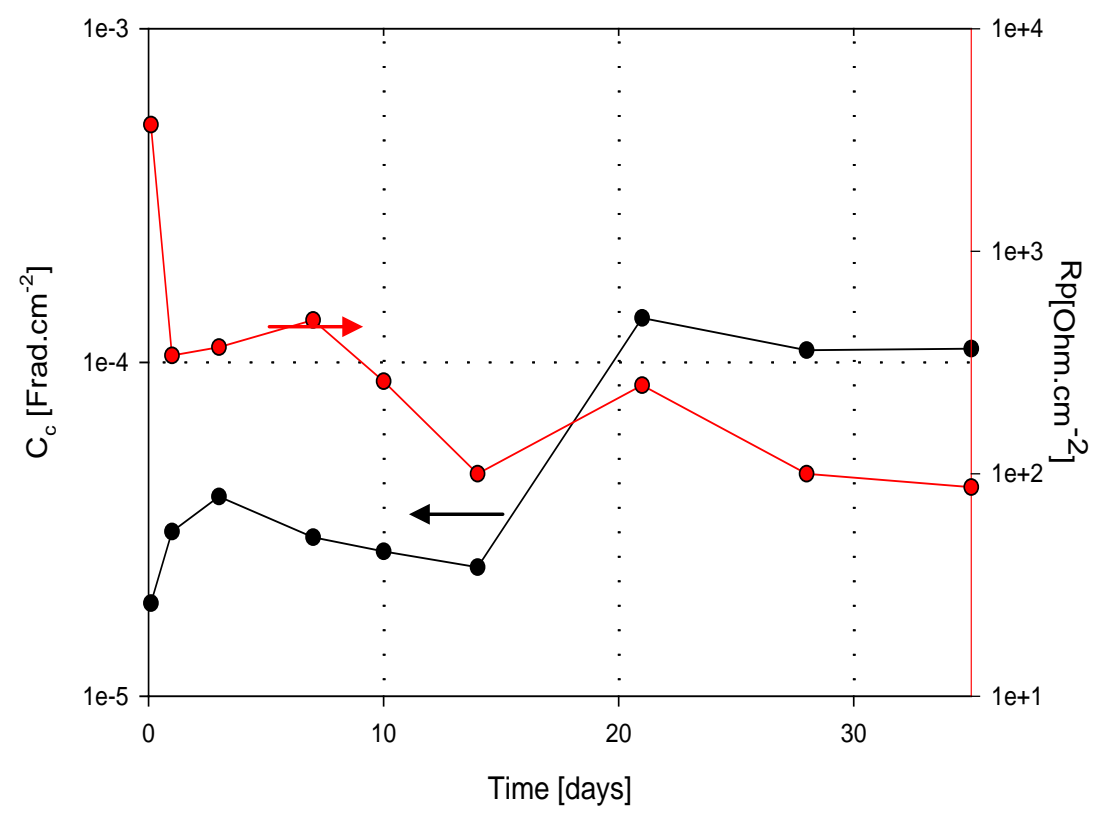

Fig. 14 Change of both coating capacitance and pore resistance of CSOL coated AA2024 in 3.5\% NaCl solution with immersion time

Although, water was diffused through the CSOL coating, the coating did not show any pitting or corrosion products. This behaviour can be explained by stability of both double layer capacitance $\left(C_{\mathrm{dl}}\right)$ and charge transfer resistance $\left(R_{\mathrm{Ct}}\right)$ as shown in Fig. 15. Here it can be seen that the $R_{\mathrm{ct}}$ values notably decrease during the first three days of immersion, however, after this initial period, the $R_{\mathrm{ct}}$ and $C_{\mathrm{dl}}$ values reach a plateau and remain almost unchanged for up to 5 weeks of immersion. $R_{\mathrm{ct}}$ and $C_{\mathrm{dl}}$ values reflect processes occurring at the coating/metal interface; which may be assumed as the metal surface absorbed a saturated amount of collagen from the coating that forming a stable barrier with the sol-gel coating [38] 


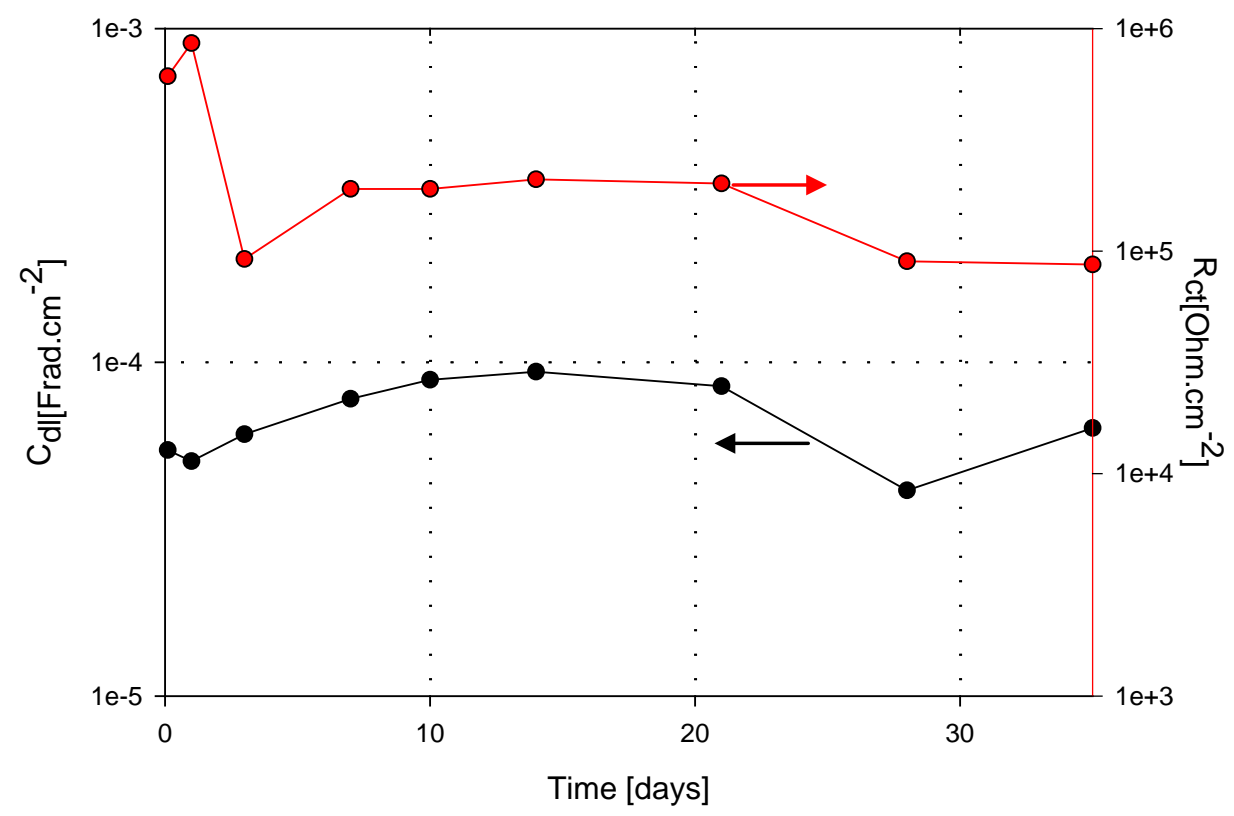

Fig. 15 Change of both double layer capacitance and charge transfer resistance of $\mathrm{CSOL}$ coated AA2024 in $3.5 \% \mathrm{NaCl}$ solution with immersion time

\subsection{Mechanical Testing}

The impact test was used to assess the resistance of the sol-gel systems with and without the addition of collagen. Coated specimens were subjected to a $1 \mathrm{~kg}$ steel ball dropping from $1 \mathrm{~m}$ height. No specimens showed any visible shattering, chipping, or cracking. The mandrel test has been conducted on samples coated with and without collagen and all samples successfully passed bending under $2 \mathrm{~mm}$ mandrel diameter without any visible signs of cracks.

Results of the pendulum test conducted on CSOL coated AA2024 samples achieved an average of 184 cycles, whereas test samples of SOL recorded an average of 190 cycles. This is a 3\% difference which indicates that the hardness resistance has remained almost unchanged upon the addition of the collagen to the coating.

The combined hardness of coated samples has been obtained using the Rockwell $\mathrm{C}$ hardness test. Test samples have been tested under $15 \mathrm{~N}$ loads. Average HRC value is 43 for the silica coated samples and 36 for Collagen coated ones.

Results of the Knoop indentation hardness test showed an average value for the SOL coated samples of 258 and 224 for the CSOL coated ones. Since higher Knoop values mean higher hardness, consequently this means that the addition of college decreases coating hardness.

The cross cut test has been applied to both SOL and CSOL coated samples to evaluate the adhesion performance. Furthermore, this test has been applied to the samples before and after immersion in $3.5 \% \mathrm{NaCl}$ solution for 24 hours in order to assess the influence of water uptake on the adhesion properties of coatings. The cross cut test of the dry samples did not show any signs of delamination after performing the test ten times on the same area (figures not presented here). When performing the test on wet samples, the CSOL ones do not exhibit distinguish different behaviour than that of 
SOL samples, where delamination is hardly visible at two scratch lines (arrows as shown in Fig. 16).

From the above results of the mechanical testing, it can be concluded that the addition of collagen to the silica sol-gel coating has not significantly changed the mechanical properties.
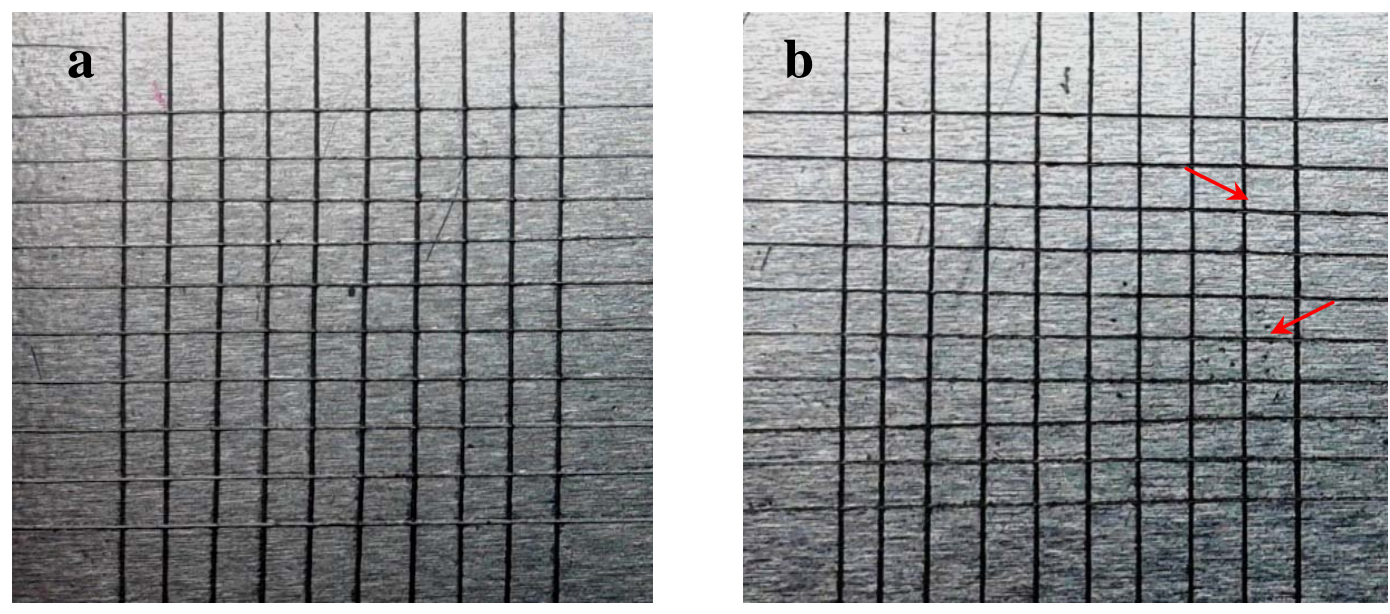

Fig. 16 Tape test results (a) with Collagen and (b) without Collagen 


\section{Conclusions}

Collagen has successfully been extracted from fish scales. The extracted collagen powder dissolved completely in acid catalysed silica sol-gel coating. The addition of collagen to the silica sol-gel coating improved the long term corrosion resistance of the coated AA2024 substrate. The mechanical properties of the new collagen/silica sol-gel coating remained almost unchanged with respect to the silica sol-gel coating.

\section{References}

1. Vargel, C., M. Jacques, and D.M.P. Schmidt, Corrosion of Aluminium. 2004, Amsterdam: Elsevier.

2. Akid, R., The Handbook of Advanced Materials: Enabling New Designs. 2004, John Wiley \& Sons, Inc.: Hoboken, New Jersey, USA. p. 487-540.

3. Health, N.I.f.O.S.a., Chromium(Vi) Oxide, U. National Institute for Occupational Safety and Health, Editor. 2009: USA.

4. Zandi Zand, R., K. Verbeken, and A. Adriaens, Corrosion resistance performance of cerium doped silica sol-gel coatings on 304L stainless steel. Progress in Organic Coatings, 2012. 75(4): p. 463-473.

5. Yasakau, K.A., et al., Active corrosion protection of AA2024 by sol-gel coatings with cerium molybdate nanowires. Electrochimica Acta, 2013. 112(0): p. 236-246.

6. Vignesh, R.B. and M.G. Sethuraman, Corrosion protection behaviour of sol-gel derived N,N-dimethylthiourea doped 3-glycidoxypropyltrimethoxysilane on aluminium. Progress in Organic Coatings, 2014. 77(1): p. 136-141.

7. Marsal, A., et al., Mechanical properties and tribological behavior of a silica or/and alumina coating prepared by sol-gel route on stainless steel. Surface and Coatings Technology, 2013. 237(0): p. 234-240.

8. López, A.J., A. Ureña, and J. Rams, Wear improvement of sol-gel silica coatings on A380/SiCp aluminium composite substrate by diode laser sintering. Materials \& Design, 2011. 32(7): p. 3865-3875.

9. López, A.J., A. Ureña, and J. Rams, Wear resistant coatings: Silica sol-gel reinforced with carbon nanotubes. Thin Solid Films, 2011. 519(22): p. 79047910.

10. Akid, R., M. Gobara, and H. Wang, Corrosion protection performance of novel hybrid polyaniline/sol-gel coatings on an aluminium 2024 alloy in neutral, alkaline and acidic solutions. Electrochimica Acta, 2011 56: p. 2483-2492.

11. Kumar, N., et al., Effect of functional groups (methyl, phenyl) on organicinorganic hybrid sol-gel silica coatings on surface modified SS 316. Ceramics International, 2012. 38(8): p. 6565-6572.

12. Hamdy, S. and P. Butt, Environmentally Compliant Silica Conversion Coatings prepared by sol-gel Method for Aluminium Alloys. Surface and Coatings Technology, 2006. 201(1-2): p. 401-407.

13. Akid, R., M. Gobara, and H. Wang, Corrosion protection performance of novel hybrid polyaniline/sol-gel coatings on an aluminium 2024 alloy in neutral, alkaline and acidic solutions. Electrochimica Acta, 2011. 56(5): p. 2483-2492.

14. Zeng, F., et al., Supramolecular polymer gel with multi stimuli responsive, selfhealing and erasable properties generated by host-guest interactions. Polymer, 2013. 54(26): p. 6929-6935. 
15. Bentiss, F., et al., 2,5-Bis(n-methoxyphenyl)-1,3,4-oxadiazoles used as corrosion inhibitors in acidic media: correlation between inhibition efficiency and chemical structure. Corrosion Science, 2002. 44(10): p. 2271-2289.

16. Lebrini, M., et al., Electrochemical and quantum chemical studies of new thiadiazole derivatives adsorption on mild steel in normal hydrochloric acid medium. Corrosion Science, 2005. 47(2): p. 485-505.

17. Quraish, M.A., et al., Inhibitive Effect of Some New Triazole Derivatives on Mild Steel Corrosion in Formic and Acetic acid. Journal of Corrosion Science and Engineering, 2006. 10.

18. Hassan, N. and R. Holze, A comparative electrochemical study of electrosorbed 2- and 4-mercaptopyridines and their application as corrosion inhibitors at C60 steel. Journal of Chemical Sciences, 2009. 121(5): p. 693-701.

19. Shi, H., et al., Cerium cinnamate as an environmentally benign inhibitor pigment for epoxy coatings on AA 2024-T3. Progress in Organic Coatings, 2014. 77(4): p. 765-773.

20. El-Hafez, G.M.A. and W.A. Badawy, The use of cysteine, N-acetyl cysteine and methionine as environmentally friendly corrosion inhibitors for $\mathrm{Cu}-10 \mathrm{Al}-5 \mathrm{Ni}$ alloy in neutral chloride solutions. Electrochimica Acta, 2013. 108(0): p. 860866.

21. Negm, N.A., et al., Gravimetric and electrochemical evaluation of environmentally friendly nonionic corrosion inhibitors for carbon steel in 1\&\#xa0;M HCl. Corrosion Science, 2012. 65(0): p. 94-103.

22. Ismail, K.M., Evaluation of cysteine as environmentally friendly corrosion inhibitor for copper in neutral and acidic chloride solutions. Electrochimica Acta, 2007. 52(28): p. 7811-7819.

23. Wang, L., et al., Characterization of collagen from the skin of Amur sturgeon (Acipenser schrenckii). Food Hydrocolloids, 2014. 38(0): p. 104-109.

24. Chiu, L.-H., et al., The effect of type II collagen on MSC osteogenic differentiation and bone defect repair. Biomaterials, 2014. 35(9): p. 2680-2691.

25. Alberti, K.A., et al., The behavior of neuronal cells on tendon-derived collagen sheets as potential substrates for nerve regeneration. Biomaterials, 2014. 35(11): p. 3551-3557.

26. International, A., A.S.f. Testing, and Materials. Annual book of ASTM Standards. 2004: American Society for Testing \& Materials.

27. Singh, P., et al., Isolation and characterisation of collagen extracted from the skin of striped catfish. Food Chemistry, 2011. 124(1): p. 97-105.

28. Ahmad, M., S. Benjakul, and S. Nalinanon, Compositional and physicochemical characteristics of acid solubilized collagen extracted from the skin of unicorn leather jacket Food Hydrocolloids, 2010. 24(6): p. 588-594.

29. Takeshi Nagai1, et al., Characterization of Acid-Soluble Collagen from Skins of Surf Smelt (Hypomesus pretiosus japonicus Brevoort). Food and Nutrition Sciences, 2010. 1: p. 59-66.

30. Wang, L., et al., Preparation and characterisation of type I and V collagens from the skin of Amur sturgeon (Acipenser schrenckii). Food Chemistry, 2014. 148(0): p. 410-414.

31. Daoud, W., J. Xin, and X. Tao, Superhydrophobic Silica Nanocomposite Coating By A Low-Temperature Process. Journal Of The American Ceramics Society, 2004. 87(9): p. 1782-1784. 
32. Vreugdenhil, A.J., et al., The role of crosslinkers in epoxy-amine crosslinked silicon sol-gel barrier protection coatings. Thin Solid Films, 2008. 517(2): p. 538-543.

33. Li, W., L. Zhu, and H. Liu, Preparation of hydrophobic anodic film on AZ91D magnesium alloy in silicate solution containing silica sol. Surface and Coatings Technology, 2006. 201(6): p. 2573-2577.

34. Szczygieł, B. and M. Kołodziej, Composite Ni/Al2O3 Coatings and Their Corrosion Resistance. Electrochimica Acta, 2005. 50(20): p. 4188-4195.

35. Jianguo, L., G. Gaoping, and Y. Chuanwei, EIS Study of Corrosion Behaviour of Organic Coating/Dacromet Composite Systems. Electrochimica Acta, 2005. 50(16-17): p. 3320-3332.

36. Buchheit, R., et al., Journal of the electrochemical society, 1977. 144: p. 2621.

37. Amin, M.A. and M.M. Ibrahim, Corrosion and corrosion control of mild steel in concentrated $\mathrm{H} 2 \mathrm{SO} 4$ solutions by a newly synthesized glycine derivative. Corrosion Science, 2011. 53(3): p. 873-885.

38. E. Hamed, et al., Corrosion inhibition of nickel in H2SO4 solution by alanine. Materials Science and Engineering, 2012. B177: p. 441- 448. 